Journal of Applied Pharmaceutical Research

Volume 7, Issue 4, Year of Publication 2019, Page 7 - 18

DOI: 10.18231/j.joapr.2019.v.7.i.4.002

Research Article

JOURNAL OF APPLIED PHARMACEUTICAL RESEARCH | JOAPR

www.japtronline.com

ISSN: $2348-0335$

\title{
SYNTHESIS AND CHARACTERIZATION OF ANTI-INFECTIVE AGENTS
}

Monika Sharma ${ }^{1}$, Sonu Sharma ${ }^{2} *$, Neha Arora ${ }^{2}$, Shreya Sharma $^{2}$, Yogesh Matta ${ }^{2}$, Sharad Sharma $^{2}$

\section{Article Information \\ Received: $19^{\text {th }}$ February 2019 \\ Revised: $28^{\text {th }}$ August 2019 \\ Accepted: $29^{\text {th }}$ September 2019}

\section{Keywords}

Detrimental, colonization,

microorganism, concentration, anti-

infective agents

\begin{abstract}
Antifungal chemotherapy depends on bio-chemical alterations between fungi and mammals. Unlike bacteria, which are prokaryotes, both fungi and mammals are eukaryotes and the biochemical differences between them are not significant. However, there are some differences (in structure \& metabolism) and focus is on these differences that act as targets for development of antifungal agents. The current recommendation of standard TB chemotherapy, called Directly observed treatment (DOTS) is a therapy of six month in which consists an first two-month phase of cure with four first-line drugs i.e. isoniazid, Rifampicin, Pyrazinamide, and Ethambutol. In this study large number of compounds is manufactured in which Most of the tested molecules showed maximum bacteriological growth inhibition at tested concentration. The combinations $(7 \mathbf{e}, 7 \mathbf{g}, 7 \mathbf{h}, 7 \mathbf{i}$ and $\mathbf{7 u}$ ) exhibited bacteriological growth inhibition at concentration of less than $40.0 \mu \mathrm{g} / \mathrm{ml}$ against both microorganisms. Compounds (7o) showed growth of inhibition at $2.5 \mu \mathrm{g} / \mathrm{ml}$ against both microorganisms. Additional challenging for all compounds at lower concentrations is mandatory to compare their activity through standard Streptomycin at its MIC to get exact MIC the manufactured combinations. Thus it can be concluded that designed 1, 3, 4oxadiazole derivatives (7a-v) were manufactured successfully using planned synthetic outline. After manufactured the molecules were characterized using spectroscopy analysis and tested for the biological activity. All combinations showed anti-bacterial action at tested concentration against both gram positive and gram negative organisms and one of the compound 7o showed activity at concentration $<2.5 \mu \mathrm{g} / \mathrm{ml}$. Thus, these $1,3,4$-oxadiazole results can then act as a potential principal for drug discovery of novel anti-infective agents.
\end{abstract}

\section{INTRODUCTION}

Antibacterial agents are using for the treatment of infective disease caused by bacteria. Anti-bacterial agents are classified in various groups [1]. Over the past few years, the development of pathogenic creatures resilient to all of the major classes of antimicrobial agents has become a serious problem. In addition,

\footnotetext{
${ }^{1}$ Maharishi Arvind College of Pharmacy, Ambabari Circle, Ambabari, Jaipur

${ }^{2}$ School of Pharmaceutical Sciences, Jaipur National University, Jagatpura, Jaipur
}

*For Correspondence: sonu.sharma283@gmail.com

\section{(C)2019 The authors}

This is an Open Access article distributed under the terms of the Creative Commons Attribution (CC BY NC), which permits unrestricted use, distribution, and reproduction in any medium, as long as the original authors and source are cited. No permission is required from the authors or the publishers. (https://creativecommons.org/licenses/by-nc/4.0/) 
advent of multi-drug resistant strains of pathogenic organisms and difficulty in treating immuno-compromised patients has caused rapid rise in the occurrence of bacteriological contagions. This frightening situation calls for the need to develop selective goal oriented drugs with advanced potency, expanded spectrum of activity, improved safety outline and activity against the multi-drug resilient strains. Thus taking into deliberation the current trend in Drug Discovery, it was needed to adopt a more target-based method for synthesis of NCEs in the present work. This has produced in a need to discover novel anti-infective agents with broad spectrum of activity against both the penetrating and impervious strains. One of the current drifts in drug discovery and development is exploration of new synthetic classes of molecules as anti-infective. As known from earlier artificial chemical classes, nitrogen hetero cycles with purines, pyrimidines, pyrazolines pyrimidinone etc are found to have varied biological activities. The work plan adopted for carrying out the present study is as follows:

1. Design the synthetic route for intermediates and final molecules.

2. Synthesis and characterization of synthesized molecules.

3. Biological evaluation of synthesized molecules.
For designed molecules, initially synthesis of 2-(2,4dichlorophenoxy) aceto hydrazide to form an intermediate. This intermediate was consequently reacted with a replaced benzoic acid to obtain final intended molecules. The proposed synthetic outlines which will be used for the synthesis of intermediate and final molecules are given below.

\section{Synthesis of 2-(2,4-dichlorophenoxy) acetohydrazide}

Substituted phenol were reacted ethyl chloro acetate using acetone as a solvent and $\mathrm{K}_{2} \mathrm{CO}_{3}$ at reflux reaction condition. Further, obtained substituted phenoxy ester was reacted with hydrazine hydrate to get the 2-(substituted phenoxy)acetohydrazide as intermediate

\section{Synthesis of 5-((2,4-dichlorophenoxy)methyl)-1,3,4-} oxadiazole-2-thiol (Scaffold-I).

For the synthesis of designed scaffold-I molecules, the intermediate 2-(substituted phenoxy) acetohydrazide was reacted with carbon disulphide in presence of potasium hydroxide and ethanol as a solvent at reflux reaction condition.

\section{Synthetic scheme for Scaffold-II}

The intermediate 2-(substitutedphenoxy) acetohydrazide was reacted with substituted benzoic acid in presence of phosphoryl trichloride to get the designed scaffold -II molecules
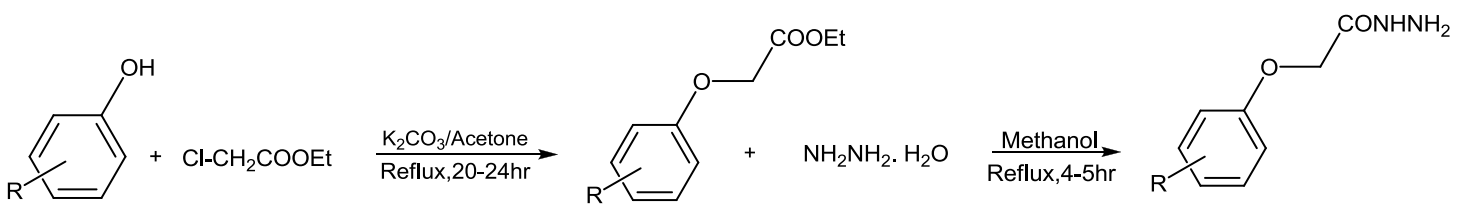

Scheme 1: General Scheme for the Synthesis of 2-(2,4-dichlorophenoxy) acetohydrazid

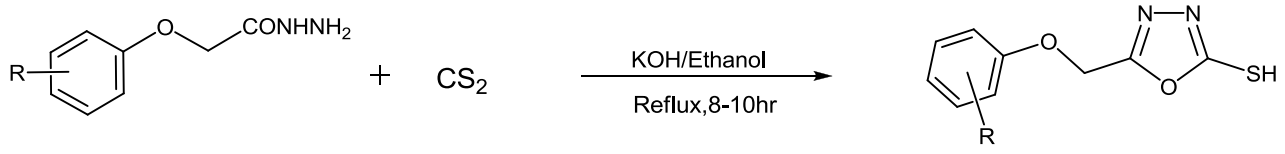

Scheme 2: General Scheme for the synthesis 5-((2,4-dichlorophenoxy)methyl)-1,3,4-oxadiazole-2-thiol
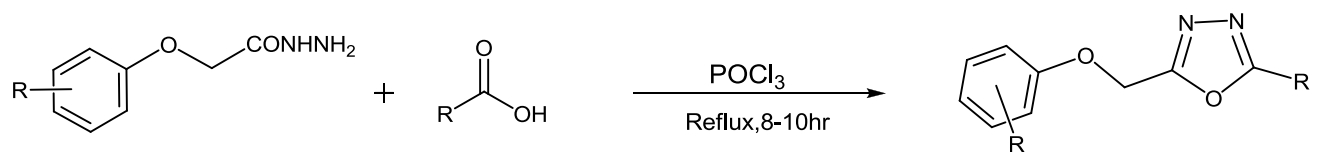

Scheme 3: General Scheme for the Synthesis of designed scaffold -II molecules

2. Synthesis and characterization of synthesized molecules.

1. Determination of melting point range

2. T.L.C. Analysis

3. Spectral Analysis

Synthesized intermediate and final molecules will be characterized using IR, ${ }^{1} \mathrm{H}$ NMR and mass spectroscopy.

IR Spectral Analysis: All synthesized molecules will be characterized to determine the characteristic functional group in the molecule.
${ }^{1}$ H NMR Spectral Analysis: One of the representatives molecules will be characterizes to determine the number \& type of hydrogen atom in the molecule.

${ }^{13}$ C NMR Spectral Analysis: One of the representatives molecules will be characterizes to determine the number \& type of carbon atom in the molecule.

Need For the Development of Novel Anti-Infective:

These study prominences on synthetic agents be appropriate to the anti-bacterial, and more precisely the anti-tubercular class 
of anti-infective agents. A instant of the disease, the goal explored to meeting the disease and present position of antitubercular drug expansion is given below. Infection caused by Mycobacterium tuberculosis remnants a foremost reason of demise. It is expectable that near about 9 million new cases of this disease occur each year. The huge popular of the world load of tuberculosis (TB) is in developing countries, which is one of the chief causes why individual $23 \%$ of the widespread active cases are currently valued to receive an suitable antituberculosis treatment Restraint to present therapy for communicable diseases has occurred because of rise of multidrug resistant strains of microbes and patients with co-operated immune system like HIV/AIDS. The collective battle of pathogens to present classes of anti-infective drugs is a vital public health concern. so there is need to improve selective target concerned with drugs with higher potency, expanded spectrum of activity, improved safety profile and activity against the multi-drug resistant strains.

The mechanisms includes

a) Transformed receptors for the medicine

b) Compact entry into the cell

c) Damage or inactivation of the medicine

d) Development of alternate metabolic pathway

e) Failure to metabolize a prodrug

Restrictions of existing classes of anti-infective agents include:

1) Narrow spectrum of act

2) Decreased strength

3) Appearance of battle

4) Adverse things

5) Selectivity

\section{MATERIALS AND METHODS}

The transparency of the intermediates and ready-made compounds were recognized by melting point, column chromatography, thin layer chromatography, infrared spectroscopy and nuclear magnetic resonance spectroscopy.

The melting point of the synthetic compounds were noted by open glass capillary method on Janki Melting Point Apparatus and matched with the stated melting points wherever applicable. ${ }^{1} \mathrm{H}-\mathrm{NMR},{ }^{13} \mathrm{C}-\mathrm{NMR}$ spectra of orientation molecule was recorded on Bruker Avance II 400 NMR spectrometer in DMSO-D6 using as a solvent. Chemical shifts were communicated in parts per million $(\delta, \mathrm{ppm})$. IR spectra were recognised using Bruker Alpha Infra-red Spectrometer.
Analytical thin layer chromatography (TLC) was carried out on pre-coated plates (silica gel G 254). [2]

The following are the chemicals used for biological testing:

1) Di-methyl sulphoxide (AR Grade, CDH , Central Drug House Pvt. Ltd., New Delhi.

2) Streptomycin, standard drugs for anti-bacterial testing were obtained from $\mathrm{CDH}$.

3) Nutrient broth and Nutrient agar for anti-bacterial testing were of microbiology grade, and found from $\mathrm{CDH}$, Central Drug House Pvt. Ltd., New Delhi.

The strains are used for challenging are as:

- Gram positive: Staphylococcus aureus.

- Gram negative: Escheria coli for antibacterial testing.

\section{General method}

- A combination of equimolar quantities of the replaced phenol and ethyl- chloro-acetate were, contained in a round bottom flask and put in 50-60 $\mathrm{ml}$ acetone and anhydrous potassium carbonate (1-2gm) was added in the mixture.

- The combination was refluxed on a soil bath with gently stirring.

- The reaction was observed by TLC.

- The reaction was continued till the replaced phenol was expended completely.

Workup: The response mixture, when chilled, was strained under vacuum to eliminate solid potassium carbonate and the filtrate thus obtained was vaporized under vacuum. The solvent was vaporized under vacuum and the remains (liquid product) thus obtained was used for the next step

\section{Mechanism of Reaction of Substituted Ethyl-2- Phenoxyacetate}

Step-I: In the early stage (the addition stage of the reaction) includes a nucleophilic outbreak on the properly positive carbon atom of ethyl chloro acetate by one of the lone pair of electrons on the oxygen of replaced phenol molecule and produce the compound-I.

Step-II: In the additional stage (the elimination stage) a chloride ion is lacking off with pair of electrons and the carbon-oxygen bond forms.

Step-III: In third stage, it is followed by removal of hydrogen ion by the chloride ion to give ester and hydrogen chloride [3]. The mechanism of this reaction is given in Figure 1 
General synthetic scheme for 2, 5 -disubstituted-1,3,4-oxadiazole derivatives
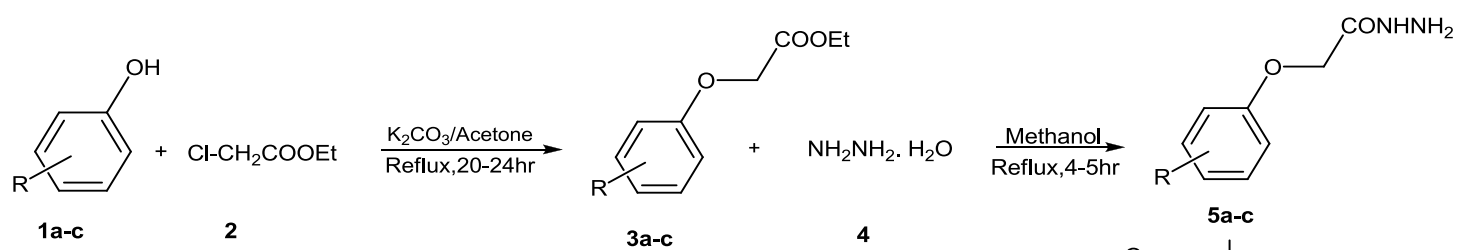

General synthetic scheme for 2,5 -disubstituted-1,3,4-oxadiazole derivatives.
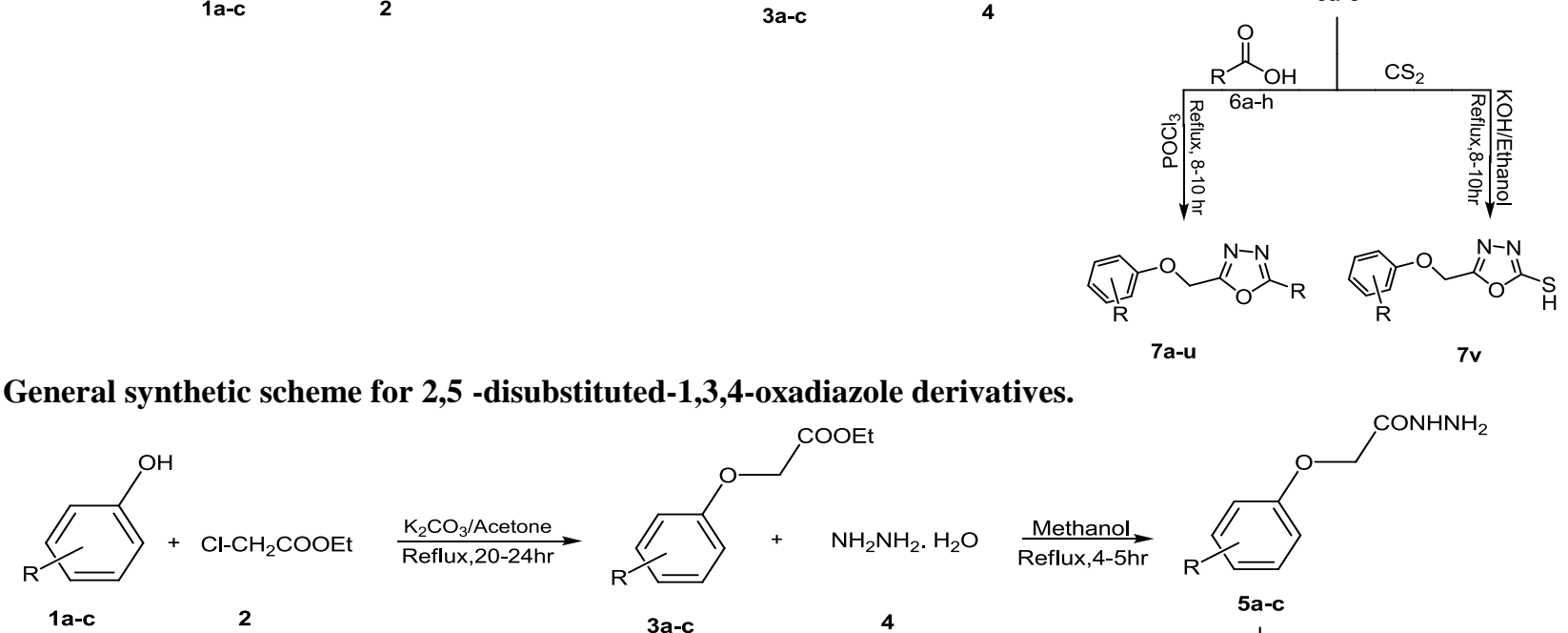

2

3a-c

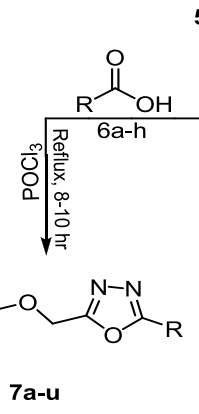

5a-c

$\mathrm{S}_{2}$
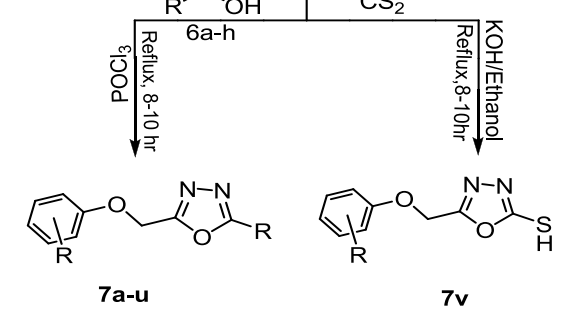

Production of Intermediates (3a-C)

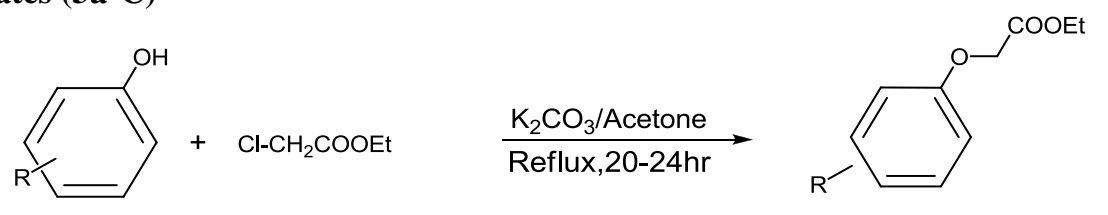

1a-c

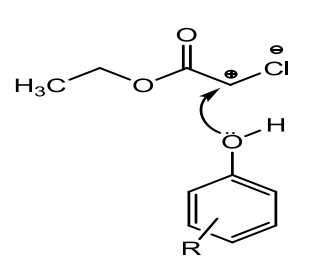

2

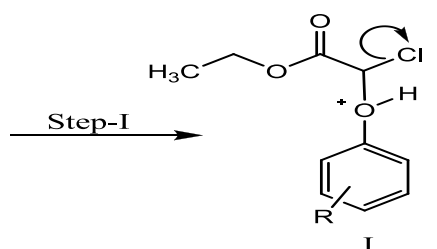

I

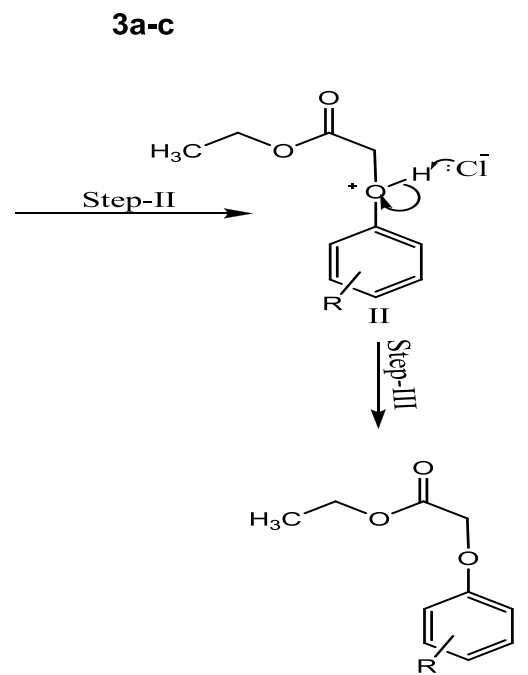

III

Figure 1: Mechanism of Replaced Ethyl 2-Phenoxyacetate Synthesis 


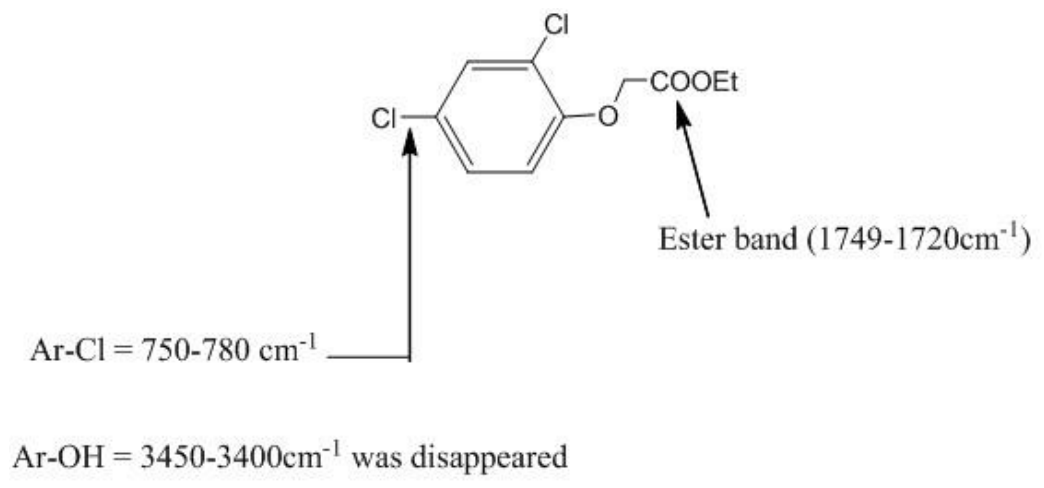

Categorization of manufactured intermediate- substituted ethyl-2-phenoxyacetate

\section{RESULTS AND DISCUSSION}
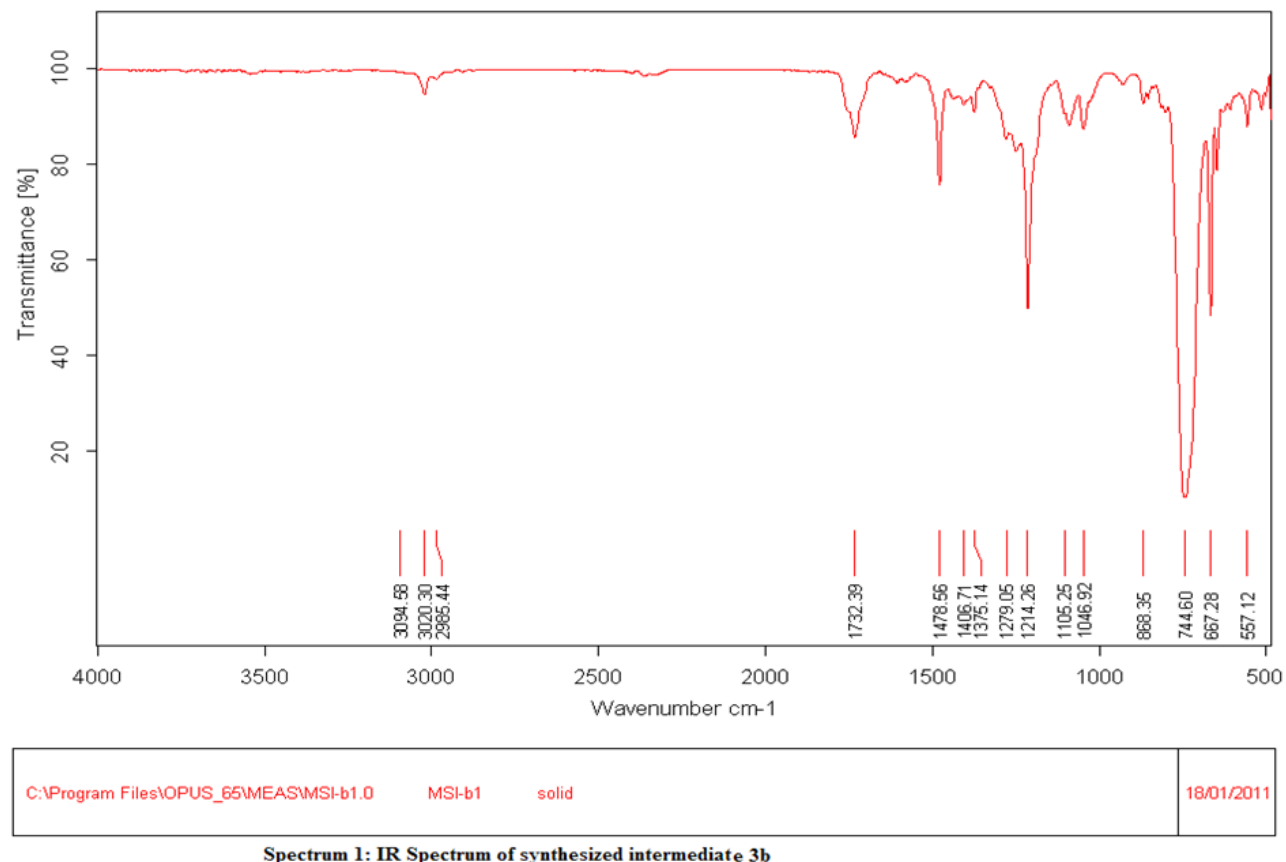

Gradient of Manufactured Intermediates (3a-C)

\begin{tabular}{|c|c|c|c|}
\hline $\begin{array}{l}\text { Sr. } \\
\text { No }\end{array}$ & $\begin{array}{l}\text { Synthesized } \\
\text { intermediate }\end{array}$ & $\begin{array}{l}\text { Yield } \\
(\%)\end{array}$ & $\operatorname{IR}\left(\mathrm{cm}^{-1}\right)$ \\
\hline $3 a$ & & 96.56 & $\begin{array}{l}3020.32,1732.94,1595.22,1497.89,1472.39,1374.38,1214.69, \\
1090.26,1044.69,746.68,696.42,666.72\end{array}$ \\
\hline $3 b$ & & 92.53 & $\begin{array}{l}3094.58,3020.30,2985.44,1732.39,1478.56,1375.14,1279.05, \\
1249.56,1214.26,1105.25,1046.92,929.20,854.11,744.60\end{array}$ \\
\hline $3 c$ & & 90.97 & $\begin{array}{l}3062.74,3019.59,1749.28,1716.97,1592.05,1338.83,1213.97, \\
951.53,848.51\end{array}$ \\
\hline
\end{tabular}

Production of Intermediates (5a-C) 


\section{General Reaction:}

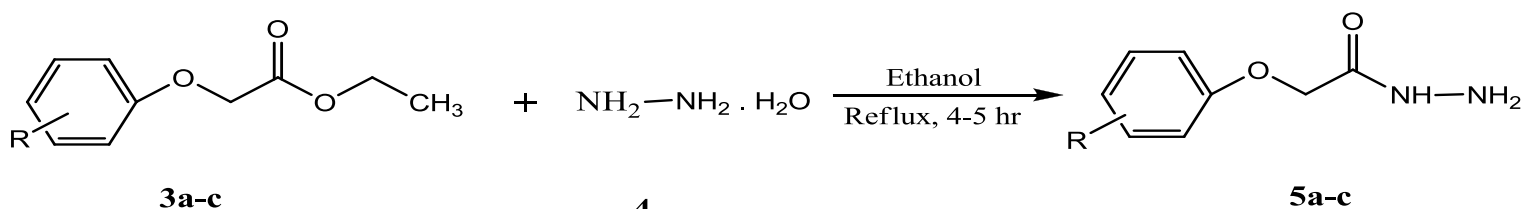

Figure 2: General synthetic scheme for substituted 2-phenoxy acetohydrazide

\section{General method}

- A solution of replaced ethyl 2-phenoxyacetate (1 mol) and hydrazine hydrate $(1.5 \mathrm{~mol})$ were kept in a round bottom flask and suspended in 50-60 ml ethanol.

- The combination was refluxed for 5-6 hr on a soil bath with gently stirring.

- The reaction was observed by TLC.

- The reaction continuous till the substituted ethyl 2phenoxyacetate was expended completely.
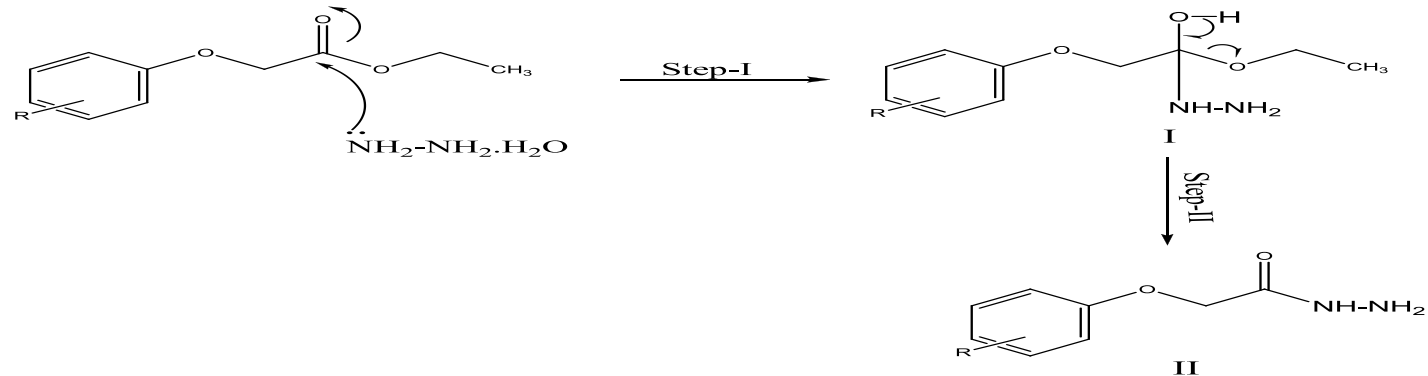

II

Figure 2: Mechanism Of Substituted 2-Phenoxy Acetohydrazide

\section{Categorization of Intermediate Substituted 2-Phenox Acetohydrazide}

Stretching Peak Corresponding To The Ester In The Range Of 1725-1745cm-1 Was Disappeared
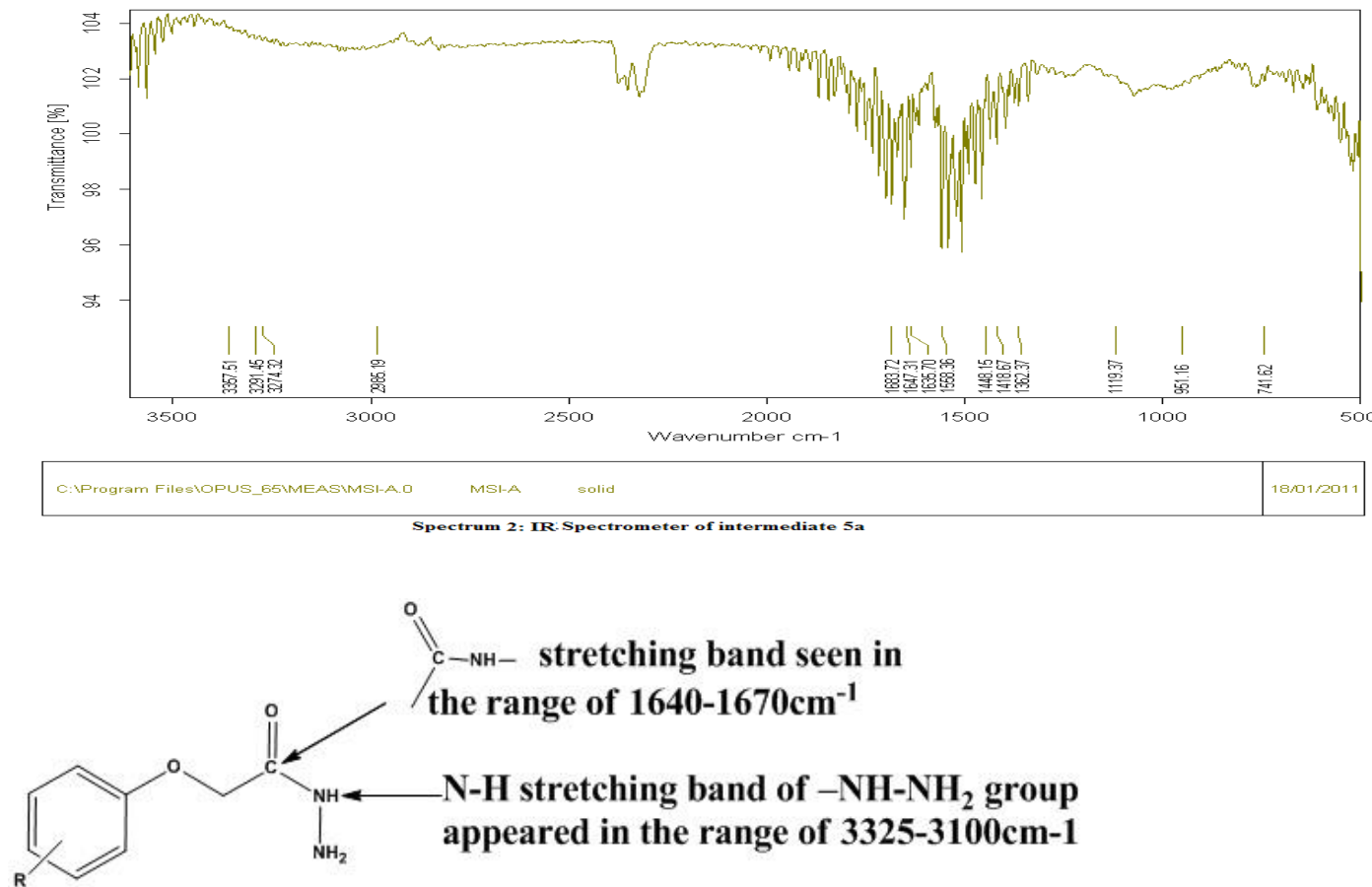

- The reaction combination, when chilled, was strained under vaccum to remove solid substituted 2phenoxyacetohydrazide.

The residue was washed with ethanol, dehydrated and used for next step.[4]

Mechanism Of Reaction Of Substituted 2-Phenoxy Acetohydrazide 
List of Manufactured Intermediates (5a-C)

\begin{tabular}{|c|c|c|c|c|}
\hline $\begin{array}{l}\text { Sr. } \\
\text { No }\end{array}$ & $\begin{array}{l}\text { Synthesized } \\
\text { intermediate }\end{array}$ & $\begin{array}{l}\text { m.p } \\
\left({ }^{\circ} \mathbf{C}\right)\end{array}$ & $\begin{array}{l}\text { Yield } \\
(\%)\end{array}$ & $\operatorname{IR}\left(\mathrm{cm}^{-1}\right)$ \\
\hline $5 a$ & & $100-105$ & 96.87 & $\begin{array}{llllll}3357.51, & 3291.45, & 3274.32, & 2985.19, & 1683.72, & 1647.31, \\
1635.70, & 1558.36, & 1448.15, & 1418.67, & 1362.37, & 1119.37, \\
951.16,741.62 & & & & \end{array}$ \\
\hline $5 b$ & $5 b$ & $150-155$ & 77.75 & $\begin{array}{llllll}3315.48, & 3259.87, & 3226.55, & 3012.11, & 1683.60, & 1647.12, \\
1558.37, & 1520.75, & 1497.24, & 1456.97, & 1387.27, & 1245.18, \\
1138.64, & 1046.29,791.81 & & & \end{array}$ \\
\hline $5 c$ & & $180-185$ & 95.58 & 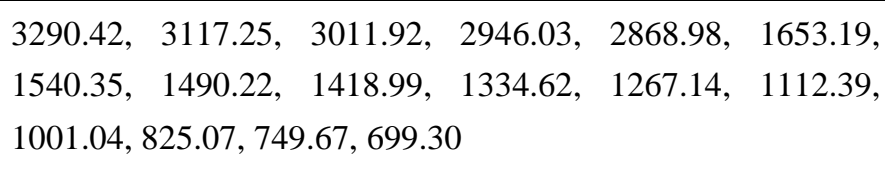 \\
\hline
\end{tabular}

Production of 2,5-Disubstituted -1,3,4-Oxadiazole (7a-U)

\section{General Reaction}

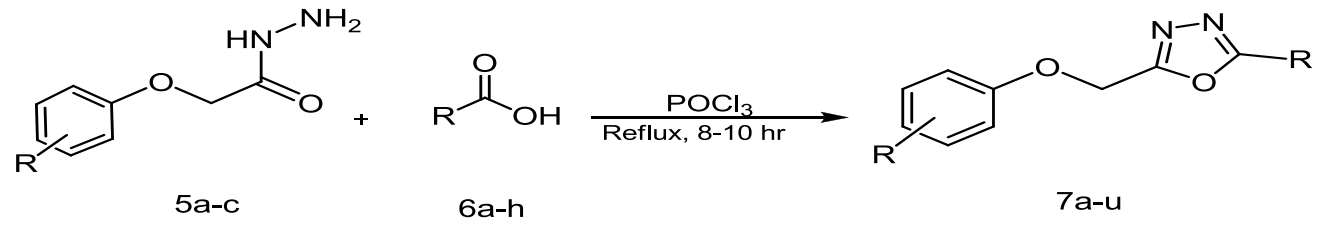

\section{General method38}

- A combination of equimolar quantities of the replaced 2-phenoxyacetohydrazide and replaced aromatic acid were, contained in a round bottom flask and suspended in $5 \mathrm{ml}$ phosphoryl tri chloride.

- The combination was refluxed on a soil bath with gently stirring.

- The reaction was observed by TLC. The reaction was continual till the substituted 2-phenoxyacetohydrazide was expended completely.

\section{Workup:}

- The reaction combination, when chilled, was slowly extinguished into crushed ice and neutralizes it with solid sodium bicarbonate.

- The solid was strained under vaccum and washed with cold water to eliminate solid sodium bicarbonate. The strained was dried.[5]

Mechanism of 2, 5-disubstituted -1,3,4-oxadiazole production:

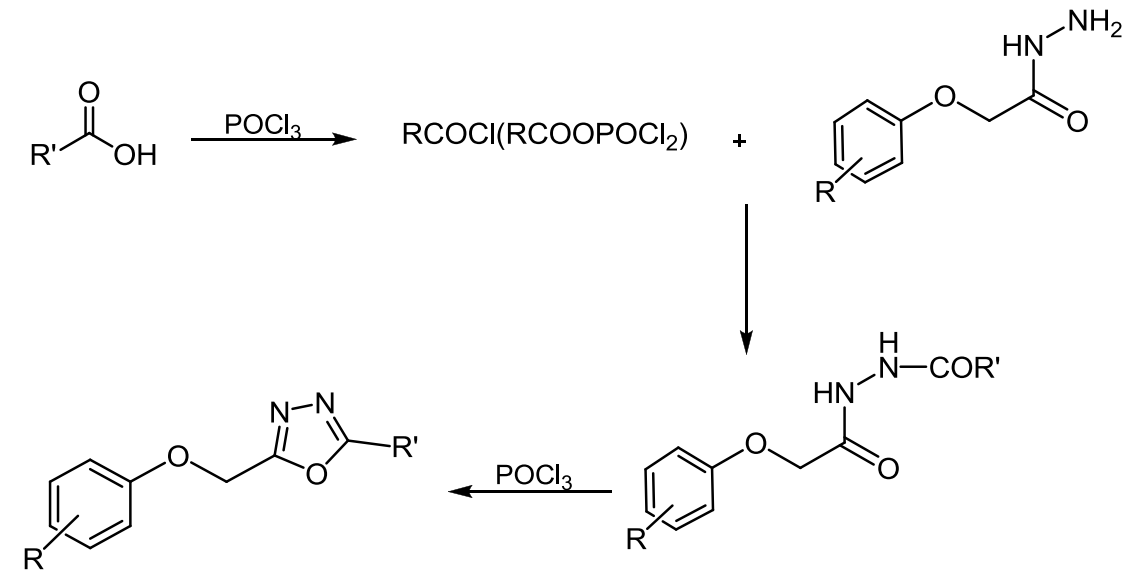




\begin{tabular}{|c|c|c|c|c|}
\hline $\begin{array}{l}\text { S. } \\
\text { No }\end{array}$ & Synthesized molecule & $\begin{array}{l}\text { m.p } \\
\left({ }^{\circ} \mathbf{C}\right)\end{array}$ & $\begin{array}{l}\text { Yield } \\
(\%)\end{array}$ & IR $\left(\mathrm{cm}^{-1}\right)$ \\
\hline $7 \mathrm{a}$ & & $95-100$ & 78.95 & $\begin{array}{l}3011.86,2977.55,2966.99,1635.48,1597.58, \\
1556.61,1436.47,1237.48,1175.15,973.13, \\
771.21,752.61\end{array}$ \\
\hline $7 b$ & & $135-140$ & 90.68 & $\begin{array}{l}3066.88,3033.69,2977.96,1662.08,1540.49, \\
1496.42,1172.78,995.29,896.02,828.55\end{array}$ \\
\hline $7 \mathrm{c}$ & & $155-160$ & 89.44 & $\begin{array}{l}3110.94,3077.17,3020.98,1669.60,1615.92, \\
1418.10,1317.71,1219.69,1090.33,772.61\end{array}$ \\
\hline $7 \mathrm{~d}$ & & $120-125$ & 90.06 & $\begin{array}{l}3067.99,3012.03,2948.61,2890.45,1652.29, \\
1540.77,1456.56,1219.55,772.51,688.50\end{array}$ \\
\hline $7 \mathrm{e}$ & & $105-110$ & 91.66 & $\begin{array}{l}3088.73,3055.12,3021.90,1598.93,1540.10, \\
1489.26,1338.88,1219.60,855.69,772.46\end{array}$ \\
\hline $7 f$ & & $125-130$ & 87.76 & $\begin{array}{l}2946.08,2838.51,1698.90,1635.69,1496.90, \\
1473.30,1362.27,1216.53,1136.47,843.65\end{array}$ \\
\hline
\end{tabular}

Mechanism Of 2, 5-Disubstituted -1, 3,4-Oxadiazole Synthesis.

List of Synthesized Molecules

\begin{tabular}{|c|c|c|c|c|}
\hline S.NO & Synthesized Molecule & $\mathbf{M . P}\left({ }^{\circ} \mathbf{C}\right)$ & Yield (\%) & IR $\left(\mathbf{C M}^{-1}\right)$ \\
\hline $7 \mathrm{~g}$ & & $115-120$ & 85.29 & $\begin{array}{l}3094.58,3020.30,2985.44,1732,1478, \\
1375,1279,1249,1105,929,854,744\end{array}$ \\
\hline $7 \mathrm{~h}$ & & $>250$ & 88.11 & $\begin{array}{llll}3344.56, & 3274.44, & 3024.34, & 2922.61, \\
1647.19, & 1558.52, & 1558.52, & 1473.93, \\
1156.29, & 951.89,798.86\end{array}$ \\
\hline $7 \mathrm{i}$ & & $>250$ & 78.32 & $\begin{array}{l}334.31, \quad 3139.63, \quad 1558.60, \quad 1520.61, \\
1464.99,1295.24,1204.84,756.31\end{array}$ \\
\hline $7 \mathrm{j}$ & & $>250$ & 90.21 & $\begin{array}{llll}3336.78, & 2925.45, & 2854.17, & 1652.45, \\
1624.40, & 1540.76, & 1474.58, & 1435.42, \\
1388.64, & 1289.03, & 1212.89, & 1157.69, \\
1102.84, & 1072.37,799.08 & \end{array}$ \\
\hline
\end{tabular}




\begin{tabular}{|c|c|c|c|c|}
\hline $7 \mathrm{k}$ & $N-N$ & $110-115$ & 90.66 & $\begin{array}{llll}3087.57, & 2921.42, & 2872.32, & 2839.16 \\
1652.87, & 1558.45, & 1540.74, & 1464.77, \\
1339.21, & 1219.56,883.79, & 772.31, & 729.42\end{array}$ \\
\hline 71 & & $>250$ & 79.63 & $\begin{array}{llll}3177.48, & 3022.63, & 2900.55, & 1601.85, \\
1525.74, & 1474.15, & 1391.16, & 1226.00, \\
991.53,870.75,793.81,763.13 & \end{array}$ \\
\hline $7 \mathrm{~m}$ & & $>250$ & 97.30 & $\begin{array}{llll}2975.41, & 2932.90, & 1683.87, & 1647.21, \\
1558.45, & 1533.57, & 1507.23, & 1448.15, \\
1219.86,773.05 & & \end{array}$ \\
\hline $7 \mathrm{n}$ & & $140-145$ & 78.39 & 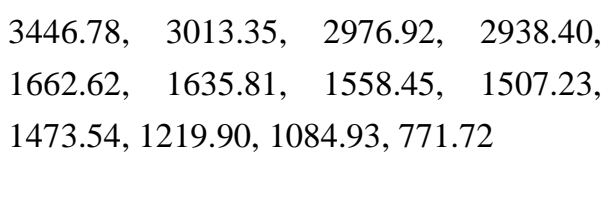 \\
\hline
\end{tabular}

\begin{tabular}{|c|c|c|c|c|}
\hline S.NO & SYNTHESIZED MOLECULE & $\mathbf{M . P}\left({ }^{\circ} \mathbf{C}\right)$ & Yield (\%) & IR $\left(\mathrm{CM}^{-1}\right)$ \\
\hline $7 \mathrm{o}$ & & $150-155$ & 90.78 & $\begin{array}{l}\text { 3065.81, 3003.83, 2946.86, 1698.96, } \\
\text { 1669.97, 1647.22, 1558.41, 1520.83, } \\
1473.33,1087.92,940.84,689.52\end{array}$ \\
\hline $7 \mathrm{p}$ & $\mathrm{O}_{2} \mathrm{~N}^{-}$ & $100-105$ & 89.19 & $\begin{array}{l}\text { 3333.63, 3295.67, 3136.42, 2907.44, } \\
1635.61,1591.39,1508.27,1340.76, \\
1251.21,1175.91,1111.09,844.68, \\
749.56\end{array}$ \\
\hline $7 \mathrm{q}$ & & $120-125$ & 93.24 & $\begin{array}{l}3296.10,3241.23,3110.94,3077.03, \\
1590.12,1507.54,1435.99,1339.53, \\
1250.66,843.50,797.27\end{array}$ \\
\hline $7 \mathrm{r}$ & & $>250$ & 91.89 & $\begin{array}{l}\text { 3054.50, 2977.28, 2908.40, 1516.22, } \\
\text { 1340.38, 1251.29, 1220.74, 1064.25, } \\
845.02,772.63\end{array}$ \\
\hline $7 \mathrm{~s}$ & & $>250$ & 92.67 & $\begin{array}{l}\text { 3024.44, 2984.84, 1621.48, 1539.88, } \\
\text { 1456.63, 1374.18, 1339.92, 1286.23, } \\
1063.36,865.57,772.36\end{array}$ \\
\hline $7 \mathrm{t}$ & & $>250$ & 92.90 & $\begin{array}{l}3039.38,2992.33,1652.36,1623.35 \\
\text { 1558.08, 1475.23, 1220.67, 1129.95, } \\
979.82,867.41,772.58\end{array}$ \\
\hline
\end{tabular}




\begin{tabular}{|l|l|l|l|l|}
\hline $7 \mathrm{u}$ & $>250$ & 94.12 & $\begin{array}{l}3088.29,3054.22,2992.16,1557.96, \\
1519.00,1489.19,1339.19,1258.85, \\
1112.13,844.76\end{array}$ \\
\hline $7 \mathrm{v}$ & & & \\
&
\end{tabular}

\section{Categorization of 2, 5-disubstituted -1,3,4-oxadiazole:}
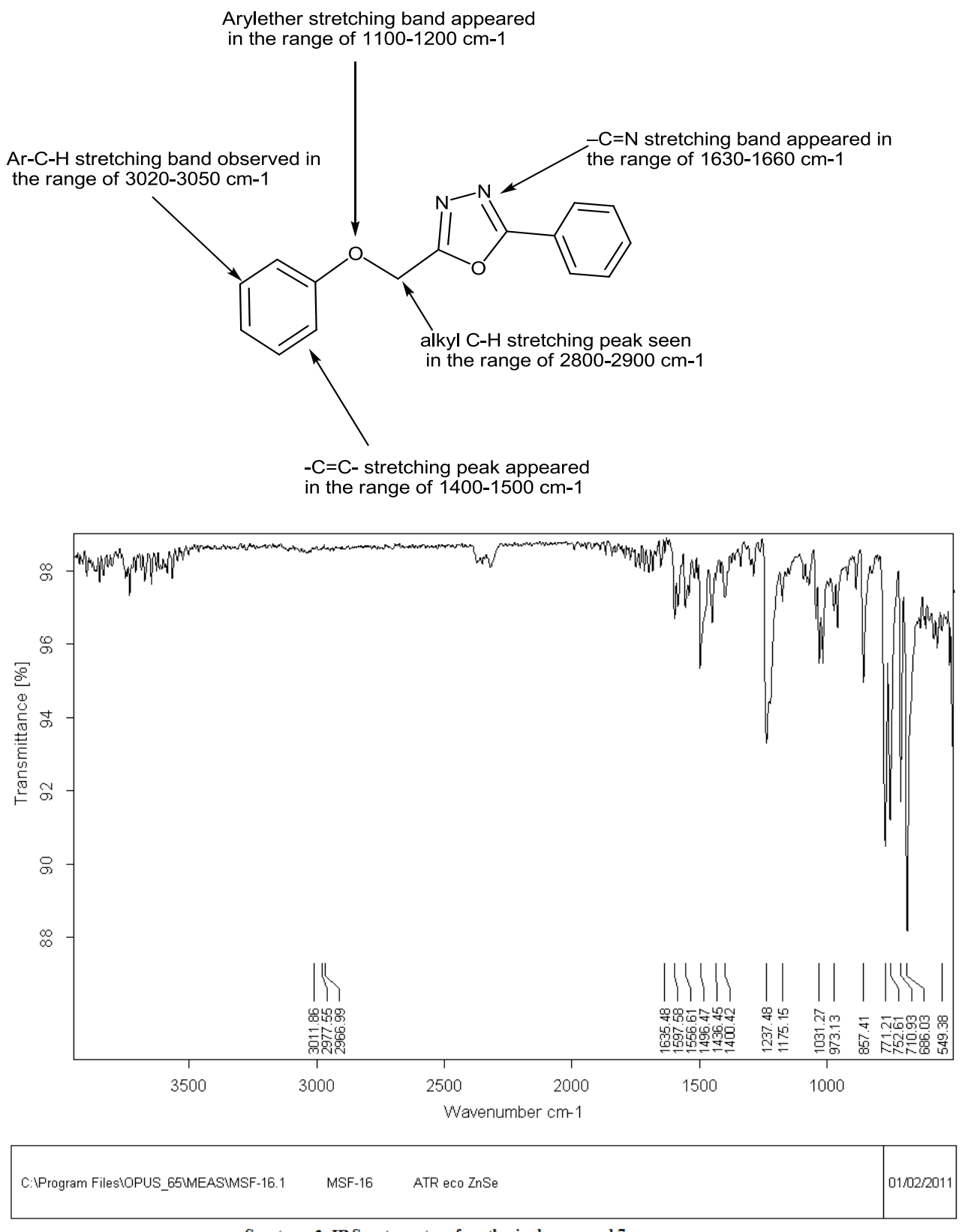

Spectrum 3: IR Spectrometer of synthesized compound 7a

${ }^{1}$ H NMR: The methylene protons appeared as a singlet at around $\delta$ 5.4. The aromatic protons appeared as multiple singlets between $\delta$ 6.9916-8.1064. Representative example is 7a.

The ${ }^{1} \mathrm{H}$ NMR values for compound 7a is listed and compared with the predicted values in the table below (Chembio office Chemdraw Ultra 11.0) (Table 1). Representative example is 7a (Spectrum 4) 

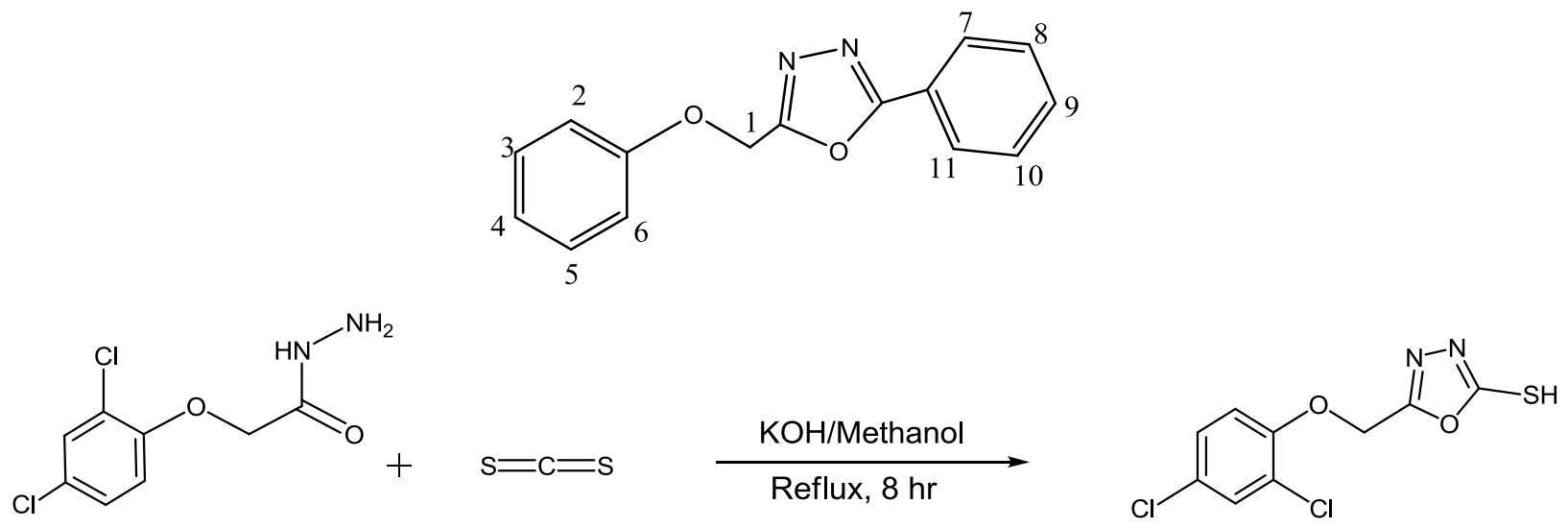

Figure 4: Synthetic pattern for 5-((2,4-dichlorophenoxy)methyl)-1,3,4-oxadiazole-2-thiol

\section{Procedure}

- The solution of 2-(2,4-dichlorophenoxy) acetohydrazide (5b) (1.0 gms, 0.033 moles), carbon disulphide (6h) $(0.97 \mathrm{ml}, 0.05$ moles$)$, and potassium hydroxide $(0.0924$ gms, 0.05 moles $)$ in methanol $(100 \mathrm{ml})$ was added. The mixture was refluxed on a soil bath with gently stirring for 8 hours.

- The reaction was observed by TLC.

\section{Workup:}

- The reaction combination, when chilled, was distilled under vaccum and the remains were dissolved in water. Acidified the solution and collected the resulting solid by separation.[6]
Mechanism of 5-((2,4-dichlorophenoxy)methyl)-1,3,4oxadiazole-2-thiol

Step-I: In the initial stage, removal of hydrogen takings place and negative charge arise on the nitrogen and compound I made.

Step-II: In the second stage adding of the reaction takes place which contains a nucleo-philic attack on the properly positive carbon atom of carbon di sulphide by one of the lone pair of electrons on the nitrogen of 2,4-dichloro acetohydrazide and produce the compound-II.

Step-III: In the third stage cyclization reaction takes place and compound III is made by the elimination of a hydrogen sulphide. [7]

The mechanism of this reaction is given in Figure 6

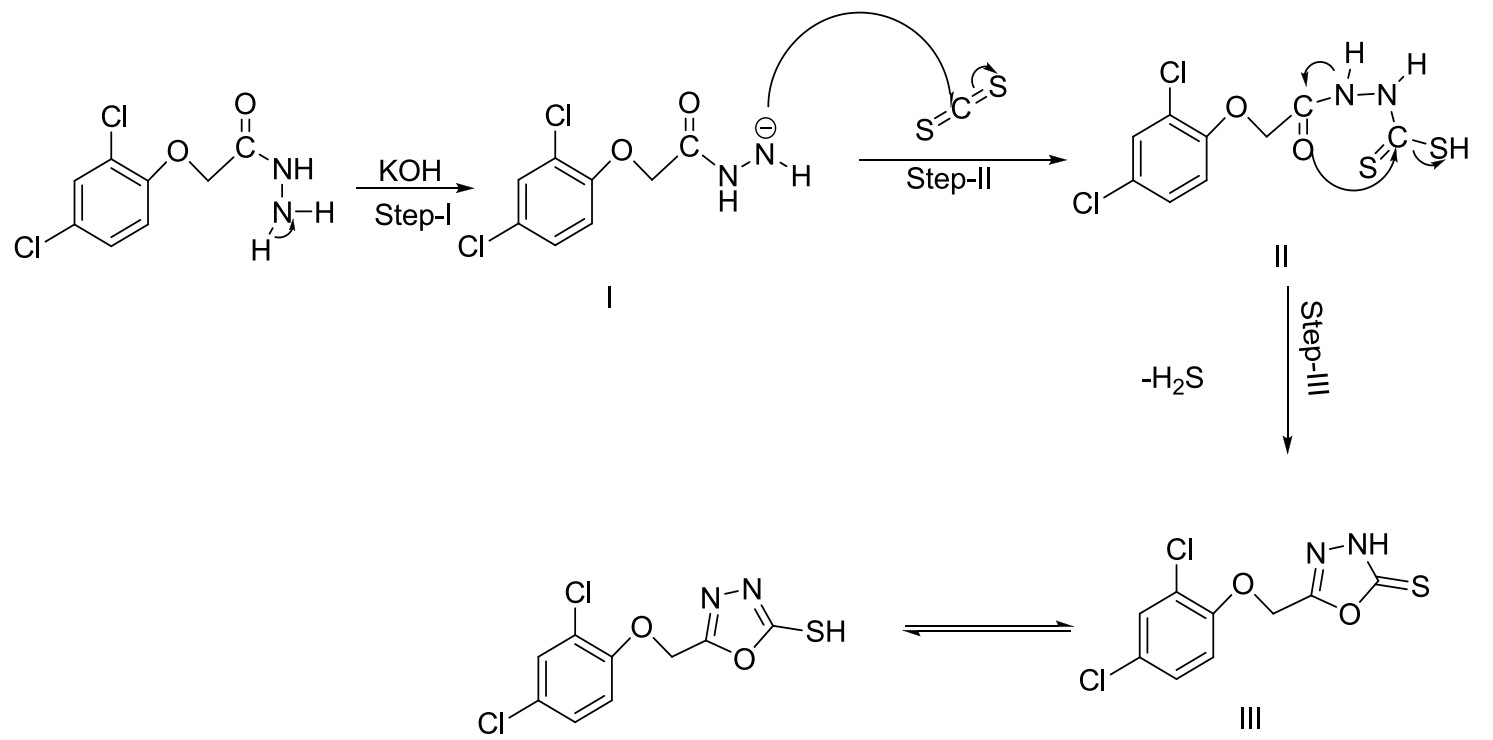

Figure 5: Mechanism of 5-((2,4-dichlorophenoxy)methyl)- 1,3,4-oxadiazole-2-thiol 


\section{CONCLUSION}

This overview of new anti-microbials in the process of drug development reflects the increased interest in the field of infectious diseases and demonstrates that, although some progress has been made, further efforts are necessary to develop more promising agents. Hopefully, these agents will overcome limitations of existing classes and will achieve the delicate balance between broad spectrum of activity and target selectivity.

Also, as mentioned above, current trend in drug discovery and development can be

1) Towards identification of new chemical classes

2) Synthesis of analogs of known chemical classes, to improve their biological profile.

3) A target-based approach for synthesis of new drugs by which a sufficient grade of selectivity can be achieved for antimicrobial activity.

\section{FINANCIAL ASSISTANCE}

Nil

\section{CONFLICT OF INTEREST}

The authors declare no conflict of interest

ACKNOWLEDGEMENT

The Authors are grateful to Maharishi Arvind College of Pharmacy, Ambabari, Jaipur for the resources and facility

\section{REFERENCES}

[1] Plattener, J., Chiron, C. Cancer and Infectious diseases. Annual Reports in Medicinal Chemistry, Elsevier Academic press, New York, pp. 163-172.

[2] William O Foye, Thomas L Lemke, David A Williams, Foye's Principles of Medicinal Chemistry. Fifth Edition, Philadelphia: Lippincott Williams and Wilkins, pp. 904923, 2002

[3] Harikishan Singh and V. K. Kapoor's, Medicinal and Pharmaceutical Chemistry. First Edition, Vallabh Publications, pp. 476-481, 2000

[4] Burger's, Medicinal Chemistry and Drug Discovery. Fifth Edition, Vol.2, A Willy interscience publications, pp. 575635,1995

[5] Tripathi, K.D, Essentials of Medical Pharmacology. Fifth Edition, Published by Jaypee Brothers Medical Publishers (P) Ltd. New Delhi, pp. 671-824, 2000

[6] K. Duncan, Identification and Validation of Novel Drug Targets in Tuberculosis. Current Pharmaceutical Design, volume 10, pp. 3185-3194, 2004

[7] Nelson, J. M., Chiller, T. M,Powers, J. H., Angulo, F. J. Food Safety, Fluoro quinolone-Resistant Campylobacter Species and the Withdrawal of Fluoro quinolones from Use in Poultry. A Public Health Success Story. Clinical Infectious Diseases. Volume 44 (7), pp. 977-80, 2007 